\title{
Cucurbitacin D induces cell cycle arrest and apoptosis by inhibiting STAT3 and NF-kB signaling in doxorubicin-resistant human breast carcinoma (MCF7/ADR) cells
}

\author{
Jin Mo Ku${ }^{1} \cdot$ Soon Re Kim ${ }^{1} \cdot$ Se Hyang Hong ${ }^{1} \cdot$ Han-Seok Choi ${ }^{1}$ • \\ Hye Sook Seo ${ }^{1} \cdot$ Yong Cheol Shin ${ }^{1} \cdot$ Seong-Gyu Ko ${ }^{1}$
}

Received: 28 April 2015/Accepted: 4 July 2015/Published online: 14 July 2015

(C) The Author(s) 2015. This article is published with open access at Springerlink.com

\begin{abstract}
Breast cancer is the most common cancer for women and is a major cause of mortality in women. Doxorubicin is a generally used chemotherapy drug for breast cancer. However, multidrug resistance of breast cancer interferes with the chemotherapy. We examined whether cucurbitacin D affects doxorubicin resistance of MCF7/ADR breast cancer cells. Cell viability was mea-

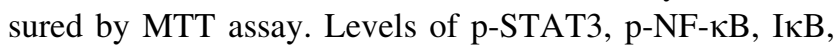
and caspases were measured by Western blot analysis. Nuclear staining of Stat 3 and NF- $\kappa \mathrm{B}$ was measured by immunocytochemistry. STAT3 and NF- $\kappa$ B transcriptional activity was detected by STAT3 and NF- $\kappa$ B luciferase reporter gene assays. Analysis of cell cycle arrest was performed by flow cytometry. Induction of apoptosis by cucurbitacin D was measured by Annexin V-FITC/propidium iodide assay. More than $90 \%$ of MCF7/ADR cells lived upon treatment with doxorubicin for $24 \mathrm{~h}$. However, upon treatment with cucurbitacin $\mathrm{D}$, cell death was more than $60 \%$. Co-administration of cucurbitacin D and doxorubicin induced apoptosis, and G2/M cell cycle arrest, and inhibited upregulated Stat 3 by doxorubicin on MCF7/ADR cells. Additionally, cucurbitacin $\mathrm{D}$ led to an increase in the I $\kappa \mathrm{B} \alpha$ level in the cytosol and a decrease in the p-NF- $\kappa \mathrm{B}$ level in the nucleus. Finally, cucurbitacin D inhibited translocation of Stat3 and NF- $\mathrm{KB}$ and decreased transcriptional activity in the nucleus. Cucurbitacin D decreases cell proliferation and induces apoptosis by inhibiting
\end{abstract}

Seong-Gyu Ko

epiko@khu.ac.kr

1 Laboratory of Clinical Biology and Pharmacogenomics, Department of Preventive Medicine, College of Oriental Medicine, Kyung Hee University, Seoul 130-701, Republic of Korea
Stat3 and NF- $\mathrm{BB}$ signaling in doxorubicin-resistant breast cancer cells. Cucurbitacin D could be used as a useful compound to treat adriamycin-resistant patients.

Keywords Breast cancer - Cucurbitacin D . Doxorubicin - Multidrug resistance $\cdot$ MCF7 cell · MCF7/ADR cell

\section{Introduction}

Breast cancer is the most common cancer for women and is a major cause of mortality in women [1]. With the development of breast cancer therapy, patient survival rates have greatly improved [2]. Doxorubicin is an anthracycline antibiotic. Anthracycline antibiotic is one of the natural product daunomycin and works by intercalating DNA. It is widely used in the treatments of several cancers [3]. Therefore, doxorubicin is a very important part of a breast cancer therapy regimen and is a generally used agent $[4,5]$. However, doxorubicin drug resistance appears in nearly $50 \%$ of treated patients [6]. And doxorubicin induces an upregulation of activated Stat 3 and NF- $\kappa B$ activation [7, 8].

Stat3 is a predictive marker of drug resistance [9]. Stat3 was significantly overexpressed in doxorubicin-resistant cells. Thus, Stat 3 activation is effective for tumor cell evasion of cancer therapy.

The NF- $\mathrm{BB}$ family contains five members: RelA/p65,

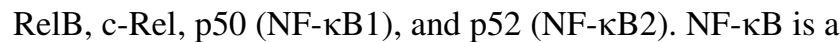
dimer composed of $\mathrm{p} 65$ and $\mathrm{p} 50$. In the cytosol, NF- $\kappa \mathrm{B}$ is inactive through interactions with the inhibitor of NF- $\kappa B$ proteins. Exposure to a variety of stimuli leads to phosphorylation of IKK $\alpha, \operatorname{IKK} \beta$, and NEMO. Phosphorylated $\mathrm{I} \kappa \mathrm{B} \alpha$ is ubiquitinated and degraded by the proteasome; 
then, NF- $\mathrm{KB}$ p65 protein is phosphorylated by IKK, and then translocated into the nucleus $[10,11]$. Activation of $\mathrm{NF}-\mathrm{\kappa B}$ promotes proliferation, inflammation, and tumorigenesis in cancer $[12,13]$.

Signal transducers and activators of transcription (Stat) proteins comprise a seven-member family of transcription factors (Stats 1, 2, 3, 4, 5a, 5b, and 6). Stats transduces signal from extracellular stimulus to the transcription of target genes. Among the Stats, Stat 3 is the most widely related with tumor development [14]. Stat 3 is activated by phosphorylation of a single tyrosine residue located at position 705 [15]. Stat3 activation in tumor cells is associated with cell proliferation, cell survival, invasion, angiogenesis, and metastasis. Recently, the Stat3 signaling pathway has been shown to confer resistance to chemotherapy-induced apoptosis in human tumors [16-19].

Cucurbitacins are a group of triterpenoids isolated from plant families Cucurbitaceae and Cruciferae. Cucurbitacins have anti-inflammatory activity and anti-cancer effects on various tumors [20]. Cucurbitacins B, D, E, I, F, O, P, and $\mathrm{Q}$ are known to suppress proliferation of tumor cells through inhibition of STAT3 phosphorylation [21]. Recently, it was reported that cucurbitacin D from Trichosanthes kirilowii has the ability to induce apoptosis in cancer. Cucurbitacin D impedes Stat 3 and NF- $\mathrm{KB}$ nuclear translocation. Cucurbitacin suppresses cell growth and produces apoptosis in various cancer cell lines [22, 23]. However, the effect of cucurbitacin D has not been investigated in breast cancer cells.

Stat3 and NF- $\mathrm{KB}$ signaling pathways play a critical role in cancer cells. Additionally, activated $\mathrm{p}-\mathrm{NF}-\kappa \mathrm{B}$ and p-Stat 3 interaction increased intercellular adhesion levels, migration, and invasion $[24,25]$. Thus, Stat 3 and NF- $\mathrm{kB}$ decreases are very important in cancer therapy. It is known that cucurbitacin D suppresses STAT3 and NF- $\kappa B$ activity inhibiting their nuclear translocation and transcriptional activity $[22,26]$. In the present study, we examined whether cucurbitacin D affected MCF7/ADR breast cancer cells.

\section{Materials and methods}

\section{Reagents}

Cucurbitacin D was purchased from Extrasynthese (Genay Cedex, France). DMSO and MTT were purchased from Sigma-Aldrich (St. Louis, MO, USA). Propidium iodide (PI) was purchased from Invitrogen (Carlsbad, CA, USA). Annexin V, Alexa Fluor 488 conjugate was obtained from Life Technologies (Eugene, OR, USA). The antibodies against cleaved caspase-8, -3, p-STAT3 (Try705), p-IкB (Ser32/36), p-NF-кB p65 (Ser536), pro-caspase-3, and total STAT3 were obtained from Cell Signaling (Danvers, MA, USA). The antibodies against IKK, PARP/p85, $\mathrm{p}$-IKK, and total NF- $\kappa \mathrm{B}$ were obtained from Santa Cruz Biotechnology (Dallas, Texas, USA). IкB antibody was obtained from Millipore. Tubulin antibody was obtained from Sigma-Aldrich (St. Louis, MO, USA). ABC kit and diaminobenzidine tetrachloride (DAB) were obtained from Vector (Burlingame, CA, USA).

\section{Cell culture}

MCF7 is a breast cancer cell line. MCF7/ADR cells have been widely used as a multidrug-resistant breast cancer cell model. MCF7/ADR cells and MCF7 breast cancer cells obtained from American-Type Culture Collection were maintained in RPMI1640 supplemented with $10 \%$ heatinactivated fetal bovine serum (Invitrogen, Carlsbad, CA, USA) and $100 \mathrm{U} / \mathrm{mL}$ antibiotic-antimycotic (Invitrogen). Cells were maintained at $37{ }^{\circ} \mathrm{C}$ in a humidified incubator with $5 \% \mathrm{CO}_{2}$.

\section{Cell viability assay}

Cell viability was measured using the MTT assay. Cells were plated in 96-well flat bottom tissue culture plates at a density of $3 \times 10^{3}$ cells/well and incubated for $24 \mathrm{~h}$. Cells were cultured for an additional $24 \mathrm{~h}$ with cucurbitacin D $(0.125-16 \mu \mathrm{g} / \mathrm{mL})$ or doxorubicin $(0.04-25 \mu \mathrm{M})$. After incubation, MTT reagents $(0.5 \mathrm{mg} / \mathrm{mL})$ were added to each well, and the plates were incubated in the dark at $37{ }^{\circ} \mathrm{C}$ for another $2 \mathrm{~h}$. The medium was removed, the formazan was dissolved in DMSO, and the optical density was measured at $570 \mathrm{~nm}$ using an ELISA plate reader.

\section{Nuclear and cytoplasmic fractionation}

Adherent cells were washed twice with phosphate-buffered saline (PBS), and then collected by scraping and pelleted by centrifugation. Cells were then transferred into a prechilled microcentrifuge tube and gently resuspended in $150 \mu \mathrm{L}$ hypotonic buffer $(20 \mathrm{mM}$ Tris- $\mathrm{HCl}, \mathrm{pH} 7.4$, $10 \mathrm{mM} \mathrm{NaCl}, 3 \mathrm{mM}$ ) by pipetting up and down several times. Cells were incubated on ice for $15 \mathrm{~min}$, and the homogenates were centrifuged for $10 \mathrm{~min}$ at $3000 \mathrm{rpm}$ at $4{ }^{\circ} \mathrm{C}$. The supernatants, which contained the cytoplasmic fraction, were transferred and saved. Nuclear pellets were resuspended in $500 \mu \mathrm{L}$ complete cell extraction buffer (100 mM Tris pH 7.4, $2 \mathrm{mM}$ sodium orthovanadate, $100 \mathrm{mM} \mathrm{NaCl}, 1 \%$ Triton X-100, $1 \mathrm{mM}$ EDTA, $10 \%$ glycerol, $1 \mathrm{mM}$ EGTA, $0.1 \%$ SDS, $1 \mathrm{mM}$ sodium fluoride, $0.5 \%$ deoxycholate, $20 \mathrm{mM}$ sodium pyrophosphate tetrabasic, $1 \mathrm{mM}$ PMSF, protease inhibitor, and dithiothreitol), and incubated on ice for $30 \mathrm{~min}$ with vortexing at 
(A)

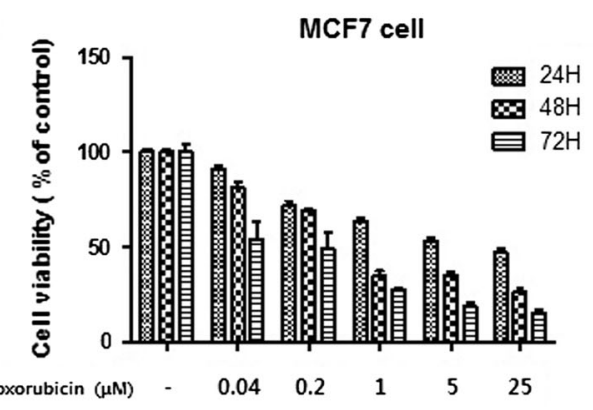

(C)

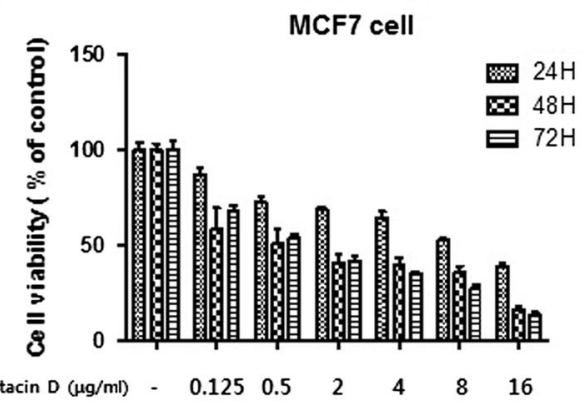

(E)

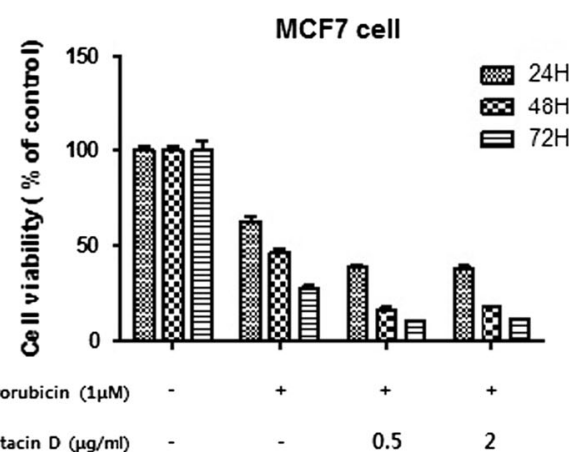

Fig. 1 Effect of doxorubicin, cucurbitacin D, and doxorubicin with cucurbitacin D on MCF7 and MCF7/ADR cell viability. MCF7 and MCF7/ADR cells were treated with different concentrations of doxorubicin, cucurbitacin $\mathrm{D}$, cucurbitacin $\mathrm{D}(0.5,2 \mu \mathrm{g} / \mathrm{mL})$, and

10 min intervals. The homogenates were centrifuged for $30 \mathrm{~min}$ at $14,000 \mathrm{rpm}$ at $4{ }^{\circ} \mathrm{C}$. The supernatants (nuclear fraction) were transferred to a clean microcentrifuge tube, and then aliquoted and stored at $-80{ }^{\circ} \mathrm{C}$ for further assay.

\section{Western blot analysis}

Cells were harvested, incubated in one volume of lysis buffer (50 mM Tris-Cl pH 7.4, $1 \% \mathrm{NP}-40,0.25 \%$ sodium deoxycholate, $0.1 \%$ SDS, $150 \mathrm{mM} \mathrm{NaCl}, 1 \mathrm{mM}$ EDTA,
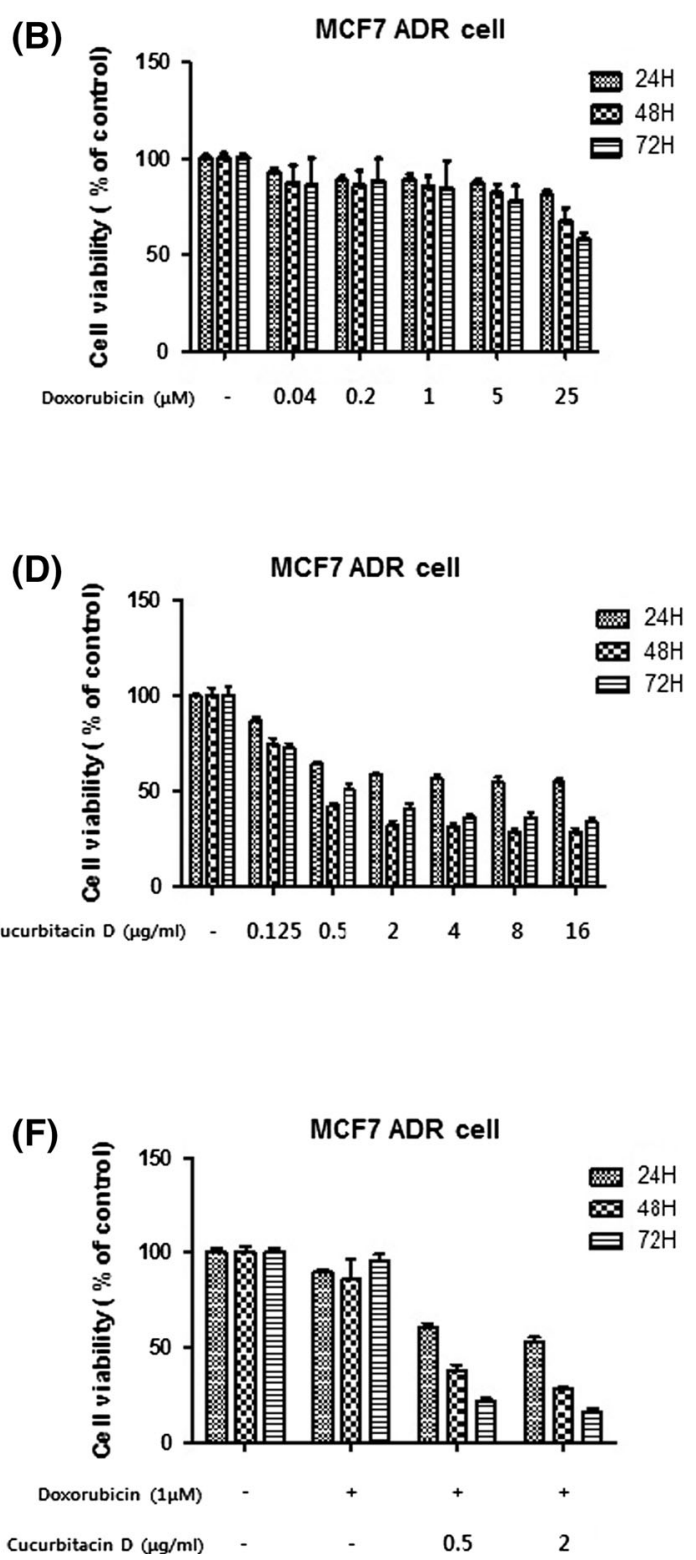

doxorubicin $(1 \mu \mathrm{M})$ for 24,48 , and $72 \mathrm{~h}$. Cell viability was then measured using the MTT assay. Each value represents the mean \pm SD. All data are $p<0.0001$ by Student $t$-test

and protease inhibitor) for $20 \mathrm{~min}$ and centrifuged at $13,000 \mathrm{rpm}$ at $4{ }^{\circ} \mathrm{C}$ for $20 \mathrm{~min}$. Aliquots containing $20 \mu \mathrm{g}$ of protein were separated by SDS-polyacrylamide gel electrophoresis using 8-12\% gels and transferred to nitrocellulose membranes (Protran nitrocellulose membrane, Whatman, UK). Membranes were blocked with $5 \%$ nonfat milk and probed with specific primary antibodies. Membranes were then incubated with horseradish peroxidase-conjugated secondary IgG antibody (Calbiochem, San Diego, CA, USA) and visualized using the enhanced 
(A)

\section{MCF7 MCF7 ADR}

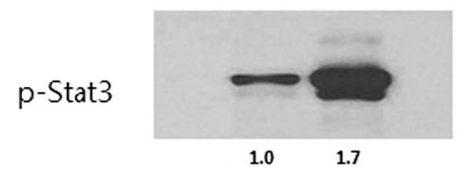

Stat3

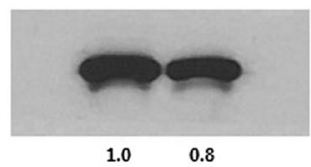

Tubulin

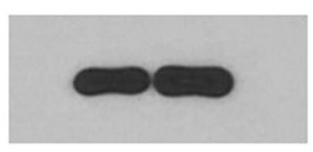

(B)

\section{MCF7 cell}

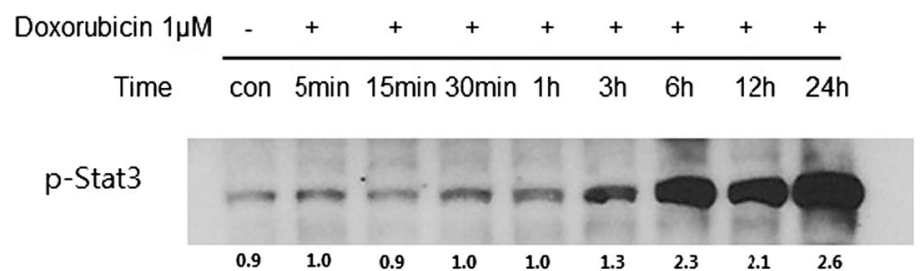

Stat3

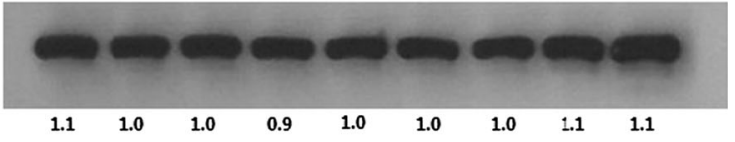

Tubulin

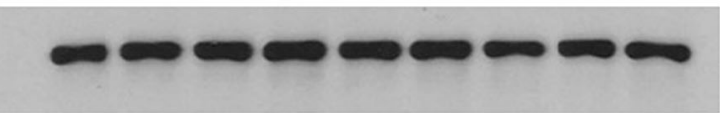

(C)

MCF7 MCF7 ADR

Doxorubicin $(1 \mu \mathrm{M})$

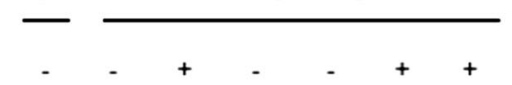

Cucurbitacin D $(\mu \mathrm{g} / \mathrm{ml})$

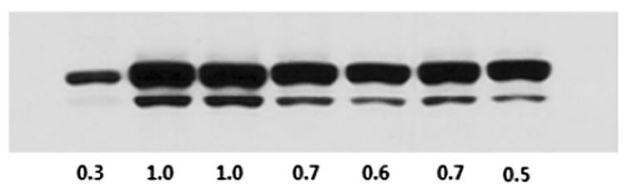

Stat3

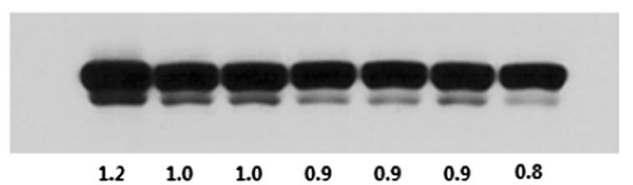

Tubulin

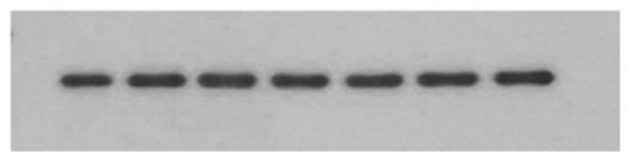

Fig. 2 Cucurbitacin D suppresses p-Stat3 expression in MCF7/ADR Cells. Constitutive activation of Stat 3 was detected in MCF7/ADR cells. p-STAT3 was strongly expressed in MCF7/ADR cells. a Doxorubicin increases constitutive STAT3 phosphorylation in a time-

chemiluminescence detection system (Amersham ECL kit, Amersham Pharmacia Biotech, Inc., Piscataway, NJ, USA).

\section{Flow cytometric analysis}

Flow cytometry was used to analyze cell cycle distribution and apoptosis. Cells were seeded in 60-mm dishes. After $24 \mathrm{~h}$, cells were cultured for an additional $24 \mathrm{~h}$ in the dependent manner in MCF7 cells. b Cucurbitacin D inhibits p-Stat3 expression in MCF7/ADR cells. c Whole-cell lysates were analyzed by Western blot with anti-pStat3, anti-Stat3, and anti-tubulin antibodies absence (control) or presence of doxorubicin $(1 \mu \mathrm{M})$ and/or cucurbitacin D $(0.5$ or $2 \mu \mathrm{g} / \mathrm{mL})$. Trypsinized cells were washed with PBS and fixed in $95 \%$ ethanol containing $0.5 \%$ Tween-20 overnight at $-20{ }^{\circ} \mathrm{C}$. After washing with PBS, cells were then incubated with $1 \mathrm{U} / \mathrm{mL}$ of RNase A and $10 \mu \mathrm{g} / \mathrm{mL}$ of PI for $30 \mathrm{~min}$ at room temperature in the dark. The DNA content in each cell nucleus was determined by a FACScalibur flow cytometer (Becton-Dickinson, San Jose, CA, USA), and the cell cycle was analyzed using ModFit LT V2.0 software. 
(A)

$$
\text { Cytosol }
$$
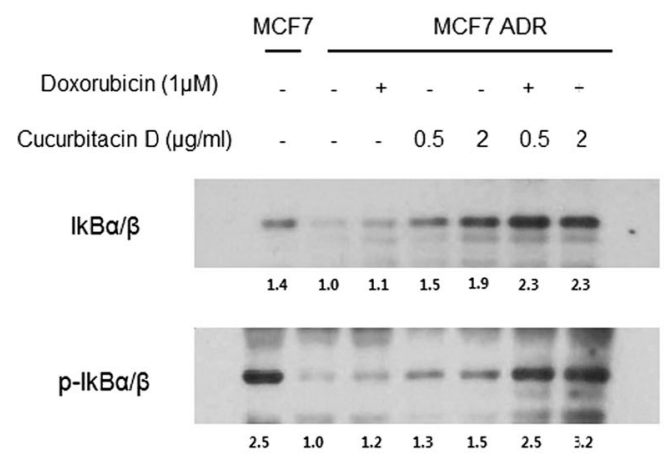

IKK

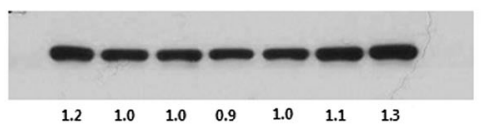

p-IKK

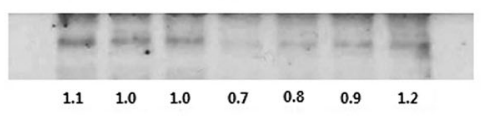

Tubulin

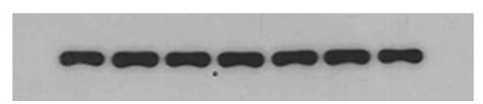

Fig. 3 Cucurbitacin D inhibits NF- $\kappa B$ signaling in MCF7/ADR cells. MCF7/ADR cells were treated with cucurbitacin D $(0.5,2 \mu \mathrm{g} / \mathrm{mL})$ in the presence and absence of doxorubicin $(1 \mu \mathrm{M})$. Nuclear and

\section{Annexin V-FITC apoptosis assay}

Cells were cultured in 60-mm dishes. After $24 \mathrm{~h}$, cells were cultured for an additional $24 \mathrm{~h}$ in the absence (control) or presence of doxorubicin $(1 \mu \mathrm{M})$ and/or cucurbitacin $\mathrm{D}(0.5$ or $2 \mu \mathrm{g} / \mathrm{mL})$. Apoptosis assay was performed with an Annexin V-FITC/PI double staining apoptosis detection kit using a flow cytometer following the manufacturer's instruction.

\section{Transfection and luciferase assay}

For the assay, MCF7/ADR cells were plated and allowed to attach by overnight incubation. The next day, the cells were transfected with control Renilla RNA (Qiagen, Venlo, Netherlands) and STAT3 CA RNA (Santa Cruz, CA, USA) in the presence of a STAT3-luciferase reporter using Lipofectamine 2000 (Invitrogen, Carlsbad, CA, USA). The cells were then treated with doxorubicin or cucurbitacin D for $6 \mathrm{~h}$. Luciferase assays were performed using a dualluciferase assay kit (Promega, Madison, WI, USA) according to the manufacturer's instructions. Briefly, cells were lysed using a passive lysis buffer. Cell lysates were then centrifuged, and the supernatant was saved for analysis. Finally, luciferase activities were determined using a luminometer (BMG Labtech, Ortenberg, Germany).
(B)
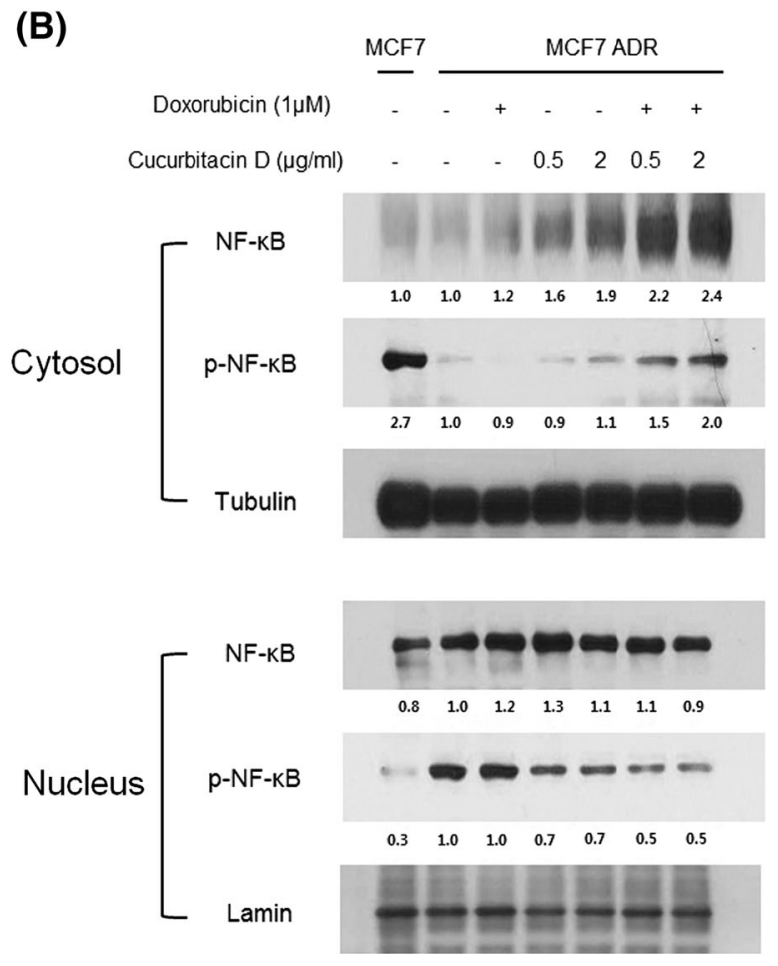

cytosolic extracts of cultured cells were then prepared and analyzed

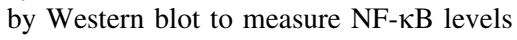

\section{Immunocytochemical analysis}

MCF7/ADR cells were inoculated at a density of $3 \times$ $10^{4}$ cells per well in eight-well chamber slides (BD Falcon, Bedford, MA). The next day, the cells were treated with cucurbitacin D or doxorubicin for $6 \mathrm{~h}$. The cells were fixed with $4 \%$ paraformaldehyde for $30 \mathrm{~min}$ and treated with $3 \%$ hydrogen peroxide $\left(\mathrm{H}_{2} \mathrm{O}_{2}\right)$ in methanol for 20 min to quench the endogenous peroxidase activity. The cells were washed with PBS, blocked with $5 \%$ BSA in PBS for $1 \mathrm{~h}$ and incubated with the anti-NF- $\kappa \mathrm{B}$ and anti-STAT3 primary antibody (1:100 dilution) overnight at $4{ }^{\circ} \mathrm{C}$. After washing with PBS, the cells were incubated with the antirabbit biotin-conjugated secondary antibody for $1 \mathrm{~h}$ at room temperature. Then, the cells were treated with Vectastain $\mathrm{ABC}$ reagent (Vector Laboratories, Inc., Burlingame, CA, USA) for $30 \mathrm{~min}$ at $4{ }^{\circ} \mathrm{C}$ and stained with DAB and hematoxylin. The cells were mounted with mounting medium and subsequently analyzed by microscopy.

\section{Statistical analysis}

The results of all experiments were expressed as the mean \pm standard deviation (SD) of at least three separate tests. A Student's $t$-test was used for single-variable 

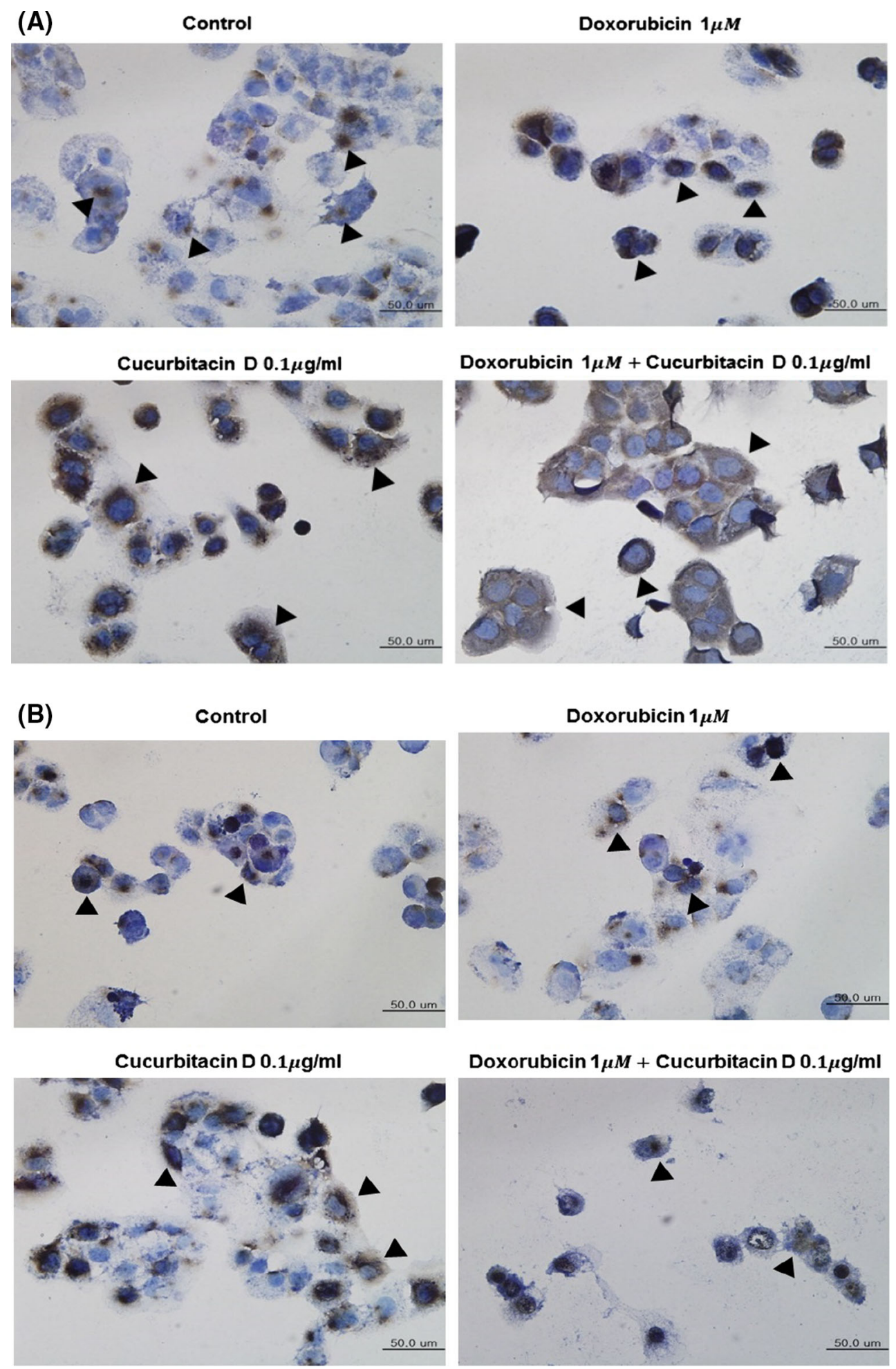

Fig. 4 Cucurbitacin D inhibits nuclear translocation of Stat3 and NF$\kappa \mathrm{B}$ in MCF7/ADR cells. MCF7/ADR cells were treated with bicin $(1 \mu \mathrm{M})$, and then submitted to immunocytochemistry for the detection of nuclear NF- $\kappa \mathrm{B}(\mathbf{a})$ and Stat3 (b) 
comparisons, and a $p$ value $<0.05$ was considered statistically significant.

\section{Results}

Effect of doxorubicin, cucurbitacin D, and doxorubicin with cucurbitacin D on MCF7 and MCF7/ADR cell viability

We investigated whether doxorubicin, cucurbitacin $\mathrm{D}$, and doxorubicin with cucurbitacin D affected the cell viability of MCF7 and MCF7/ADR cells.

For that purpose, both MCF7 and MCF7/ADR cells were treated with different concentrations of doxorubicin $(0.04,0.2,1,5$, and $25 \mu \mathrm{M})$ for 24-72 h. Cell viability was then measured by MTT assay. We found that doxorubicin significantly suppressed cell growth in a dose- and timedependent manner in MCF7. However, doxorubicin failed to decrease cell viability in MCF7/ADR cells (Fig. 1a, b). Both MCF7 and MCF7/ADR cells were treated with different concentrations of cucurbitacin $\mathrm{D}(0.125,0.5,2,4,8$, and $16 \mu \mathrm{g} / \mathrm{mL}$ ) for $24-72 \mathrm{~h}$. We found that cucurbitacin D significantly suppressed cell growth in both MCF7 and MCF7/ADR in a dose- and time-dependent manner (Fig. 1c, d). We co-treated MCF7 and MCF7/ADR cells with doxorubicin $(1 \mu \mathrm{M})$ and cucurbitacin $\mathrm{D}(0.5,2 \mu \mathrm{g} / \mathrm{mL})$ to investigate whether cucurbitacin $\mathrm{D}$ overcomes doxorubicin resistance. We found that cucurbitacin D and doxorubicin significantly suppressed cell growth in MCF7 cells, and cucurbitacin D reversed the doxorubicin-resistant cell growth of the MCF7/ADR cell line (Fig. 1e, f).

\section{Cucurbitacin D suppresses Stat 3 expression in MCF7/ADR cells}

To determine the relationship between Stat 3 and doxorubicin resistance in human breast cancer cells, we analyzed the expression of p-STAT3 and Stat 3 in MCF7/ADR cells and MCF7 cells. We found that p-Stat 3 expression was significantly overexpressed in MCF7/ADR cells than in the MCF7 cell line (Fig. 2a). Next, we determined whether doxorubicin increased p-Stat 3 expression in MCF7 cells. We found that doxorubicin alone increased p-STAT3 level in a time-dependent manner (Fig. 2b).

To further characterize the Stat3-inhibitory effect of cucurbitacin D and doxorubicin in MCF7/ADR cells, we found that cucurbitacin D decreased p-STAT3 level in the absence and presence of doxorubicin, suggesting that cucurbitacin D inhibits STAT3 signaling in MCF7/ADR cells (Fig. 2c).

\section{Cucurbitacin D inhibits the NF-кB signaling pathway in MCF7/ADR cells}

We investigated whether cucurbitacin D inhibits NF- $\mathrm{BB}$ signaling in MCF7/ADR cells. For that purpose, we treated MCF7/ADR cells with cucurbitacin D $(0.5,2 \mu \mathrm{g} / \mathrm{mL})$ and/ or doxorubicin $(1 \mu \mathrm{M})$, and we prepared nuclear and cytosolic fractions of the treated cells subjected them to Western blot analysis. We found that cucurbitacin D

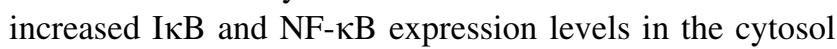
and decreased p-NF- $\kappa \mathrm{B}$ level in the nucleus (Fig. 3a, b).

\section{Cucurbitacin D suppresses Stat3 and NF-кB translocation in MCF7/ADR cells}

To confirm that cucurbitacin D inhibits nuclear translocation of Stat3 and NF- $\mathrm{KB}$, we performed immunocytochemistry on MCF7/ADR cells. We found that cucurbitacin D marked cytosol presence of STAT3 and NF$\kappa \mathrm{B}$ and decreased nuclear staining of NF- $\mathrm{\kappa B}$ (Fig. 4a) and Stat3 (Fig. 4b) in MCF7/ADR cells. This suggests that cucurbitacin D inhibits nuclear translocation of Stat 3 and $\mathrm{NF}-\kappa \mathrm{B}$.

\section{Cucurbitacin D suppresses Stat3 and NF-кB transcriptional activity}

Although cucurbitacin D inhibits Stat3 and NF- $\kappa B$ translocation ability, it is not known whether the compound can regulate Stat3 and NF- $\kappa B$ transcriptional activity. Therefore, we performed luciferase reporter gene assays to detect Stat3 and NF- $\mathrm{KB}$ transcriptional activity. We found that cucurbitacin D significantly repressed STAT3 and NF$\kappa \mathrm{B}$ transcription activity in MCF7 cells (Fig. 5a, b).

\section{Cucurbitacin D induces apoptosis and $G 2 / M$ cell cycle arrest in MCF7/ADR cells}

To investigate whether cucurbitacin D inhibits cell proliferation by promoting changes in cell cycle progression, the effect of cucurbitacin D on the cell cycle profile was assessed using flow cytometry. For this purpose, MCF7/ ADR cells were treated with cucurbitacin $\mathrm{D}(0.5 \mu \mathrm{g} / \mathrm{mL})$ and/or doxorubicin $(1 \mu \mathrm{M})$ for $24 \mathrm{~h}$. The results demonstrated that cucurbitacin D induced an increase in the subG1 and G2/M populations in MCF7/ADR cells, suggesting that cucurbitacin $\mathrm{D}$ induces $\mathrm{G} 2 / \mathrm{M}$ cell cycle arrest (Fig. 6a). We found that doxorubicin did not induce apoptosis in drug-resistant cells; however, cucurbitacin D treatment resulted in a $114 \%$ increase in apoptosis (apoptotic cells were calculated after Annexin V/PI staining) when compared to that of control group. Doxorubicin with cucurbitacin D treatment resulted in a $145 \%$ increase 

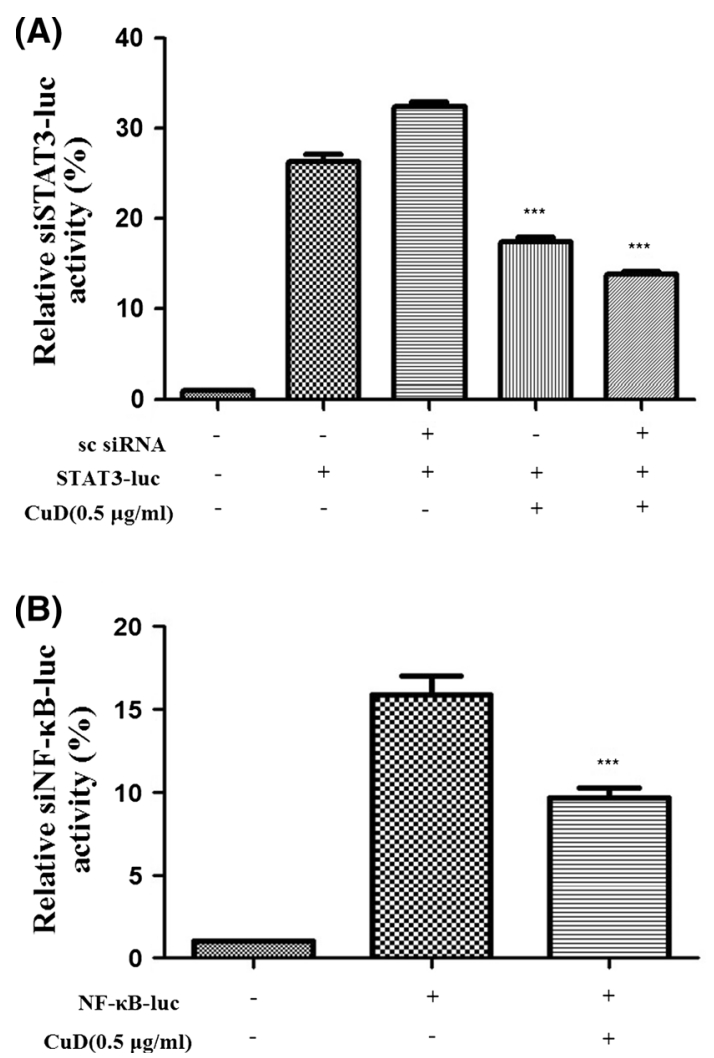

Fig. 5 Cucurbitacin D inhibits Stat3 and NF- $\kappa B$ transcription in MCF7 cells. MCF7 cells were transfected with the indicated siRNA or plasmid, and then treated with each drug for $24 \mathrm{~h}$. MCF7 cells were then treated with cucurbitacin D $(0.5 \mu \mathrm{g} / \mathrm{mL})$. Afterward, lysates were analyzed using the dual-luciferase reporter assay. Each value represents the mean $\pm \mathrm{SD}$. All data are $p<0.0001$ by Student $t$-test

in apoptosis (apoptotic cells were calculated after Annexin V/PI staining) when compared to that of doxorubicin control group (Fig. 6b). Because the sub-G1 level was increased by cucurbitacin D treatment, we performed Annexin V/PI staining flow cytometry analysis to detect apoptotic cells. To confirm that caspase activation is involved in cucurbitacin D-induced apoptosis in MCF7/ ADR cells, we found that cucurbitacin D up-regulated the levels of cleaved caspase- 3 , cleaved caspase- 8 , and cleaved PARP in MCF7/ADR cells (Fig. 6c).

\section{Discussion}

In this study, we found that cucurbitacin D decreased cell proliferation and induced apoptosis by inhibiting Stat 3 and NF- $\kappa \mathrm{B}$ signaling in doxorubicin-resistant breast cancer cells, MCF7/ADR.

Among the Stat proteins, persistent activation of Stat 3 is detected in human cancer cell lines and tumor tissues [24, 25]. These include breast cancer, lung cancer, pancreatic
Fig. 6 Cucurbitacin D induces G2/M cell cycle arrest and apoptosis in MCF7/ADR cells. MCF7/ADR cells were treated with cucurbitacin $\mathrm{D}(0.5 \mu \mathrm{g} / \mathrm{mL})$ in the presence and absence of doxorubicin $(1 \mu \mathrm{M})$ for $24 \mathrm{~h}$. Cell cycle distribution was analyzed using a FACS flow cytometer (a). MCF7/ADR cells were treated with the indicated drugs for $24 \mathrm{~h}$ and subjected to Annexin V/PI assay. b Effect of cucurbitacin D on the expression of cleaved caspase-3, cleaved caspase-8, and cleaved PARP. MCF7/ADR cells were treated with cucurbitacin $\mathrm{D}(0.5 \mu \mathrm{g} / \mathrm{mL})$ in the presence and absence of doxorubicin $(1 \mu \mathrm{M})$ for $24 \mathrm{~h}$. The cell lysates were subjected to Western blot analysis using specific antibodies (c)

cancer, head and neck cancer, prostate cancer, ovarian cancer, melanoma, leukemias, and lymphomas. Stat3 activation in tumor cells is associated with cell proliferation, cell survival, invasion, angiogenesis, and metastasis [27]. Doxorubicin-treated cancer cells contained activated Stat3. Stat3 activation is linked to the development of doxorubicin resistance in cancer cell lines [28]. Stat3 is a predictive marker of drug resistance [9]. Therefore, we analyzed the expression and activation of Stat3 in MCF7 and doxorubicin-resistant MCF7/ADR cells. We also investigated whether Stat3 activation was associated with doxorubicin resistance in MCF7/ADR. We found that Stat3 was constitutively activated in MCF7/ADR, and this activation was disrupted by cucurbitacin $\mathrm{D}$. This result suggests that cucurbitacin D inhibits cell growth and induces apoptosis by inhibiting Stat3 signaling. Additionally, cucurbitacin D inhibits nuclear translocation of Stat3, as revealed by immunocytochemistry.

$\mathrm{NF}-\kappa \mathrm{B}$ has an important effect on cell growth and inhibition of apoptosis. Activation of NF- $\mathrm{KB}$ promotes proliferation, inflammation, and tumorigenesis in cancer [12-14]. To investigate the mechanism by which cucurbitacin D decreases cell growth and induces apoptosis in MCF7/ADR cells, we made nuclear and cytosolic fractions and analyzed them by Western blot to measure the levels of $\mathrm{NF}-\kappa \mathrm{B}$ signaling molecules. We found that cucurbitacin D increased I $\mathrm{KB}$ level in the cytosol and suppressed the nuclear translocation of $\mathrm{p}-\mathrm{NF}-\mathrm{\kappa B}$, resulting in apoptosis. Cucurbitacin D suppressed cell growth in both MCF7 and MCF7/ADR cells in a dose- and time-dependent manner. This growth inhibition was accompanied by cell morphology changes and cell cycle arrest. The cell cycle is controlled by numerous mechanisms ensuring correct cell division. Additionally, cancer progression is related to aberrant cell cycle regulation [29]. G2/M DNA damage checkpoint consists of an arrest of the cell in G2 just before mitotic entry in response to genotoxic stress [30]. We found that cucurbitacin D increases the sub-G1 population and G2/M population in MCF7/ADR cells. To confirm apoptosis, we performed the Annexin V-FITC/PI assay and 


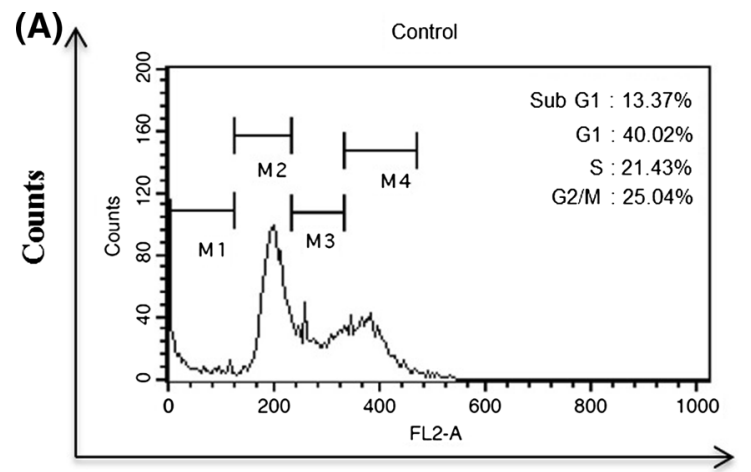

DNA Content

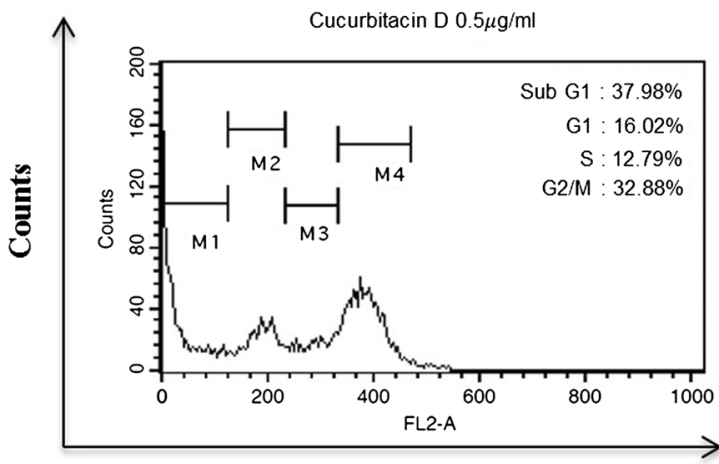

DNA Content

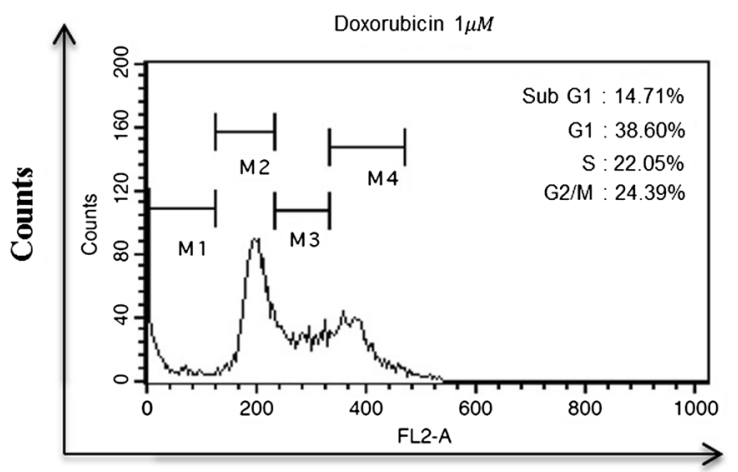

DNA Content

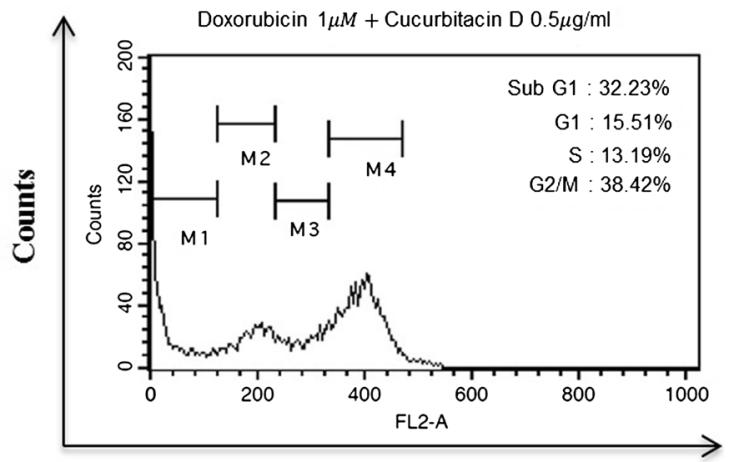

DNA Content

(C)

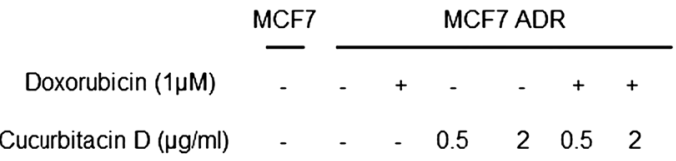

Cleaved Caspase 3

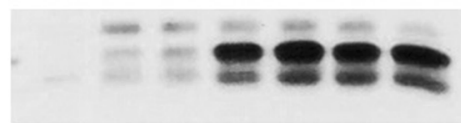

$\begin{array}{lllllll}0.7 & 1.0 & 1.2 & 4.2 & 5.0 & 4.7 & 4.9\end{array}$

pro Caspase 3
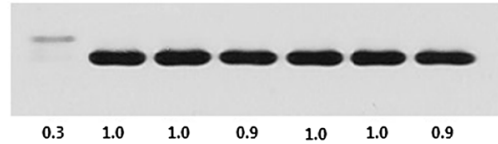

Cleaved Caspase 8
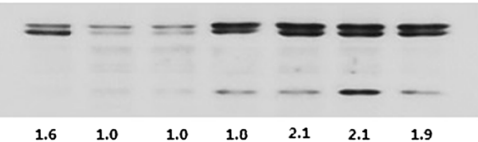

Parp
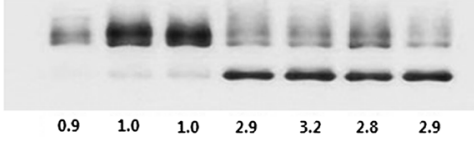

Tubulin 
(B)
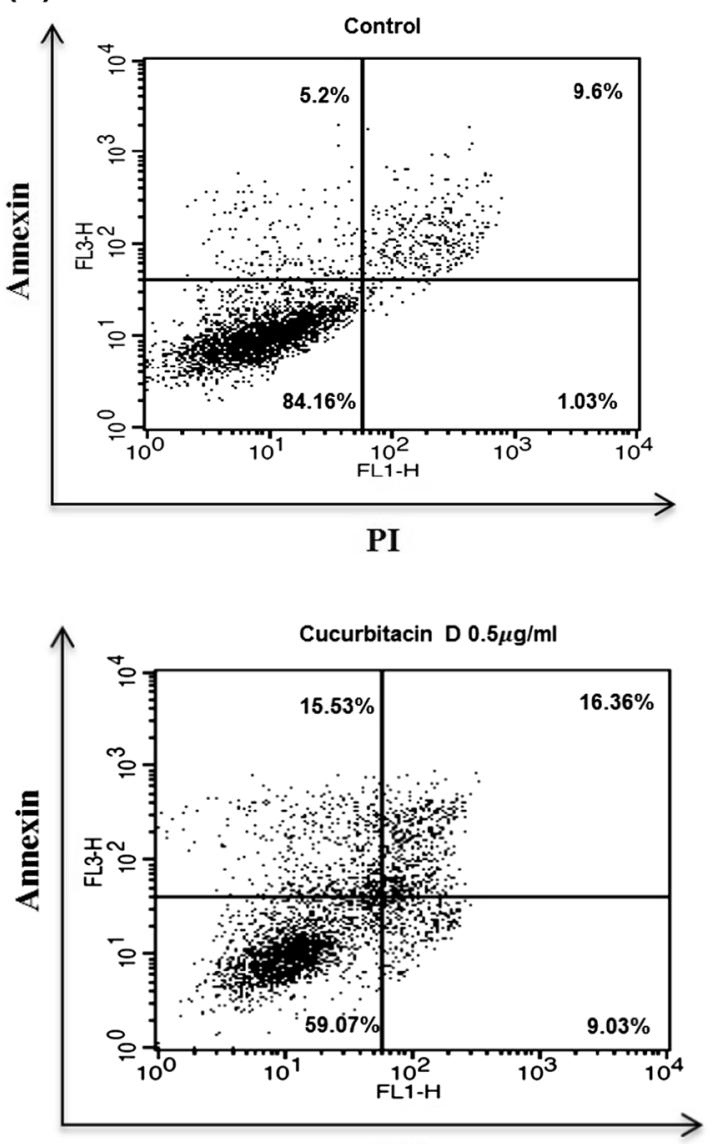

PI

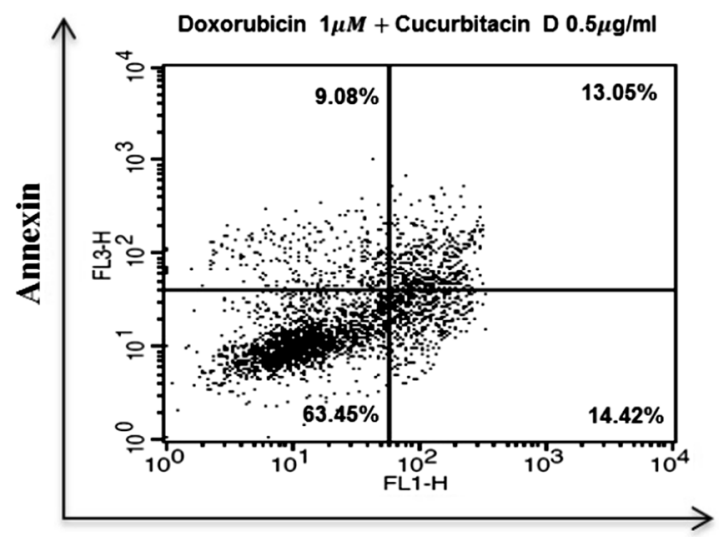

PI
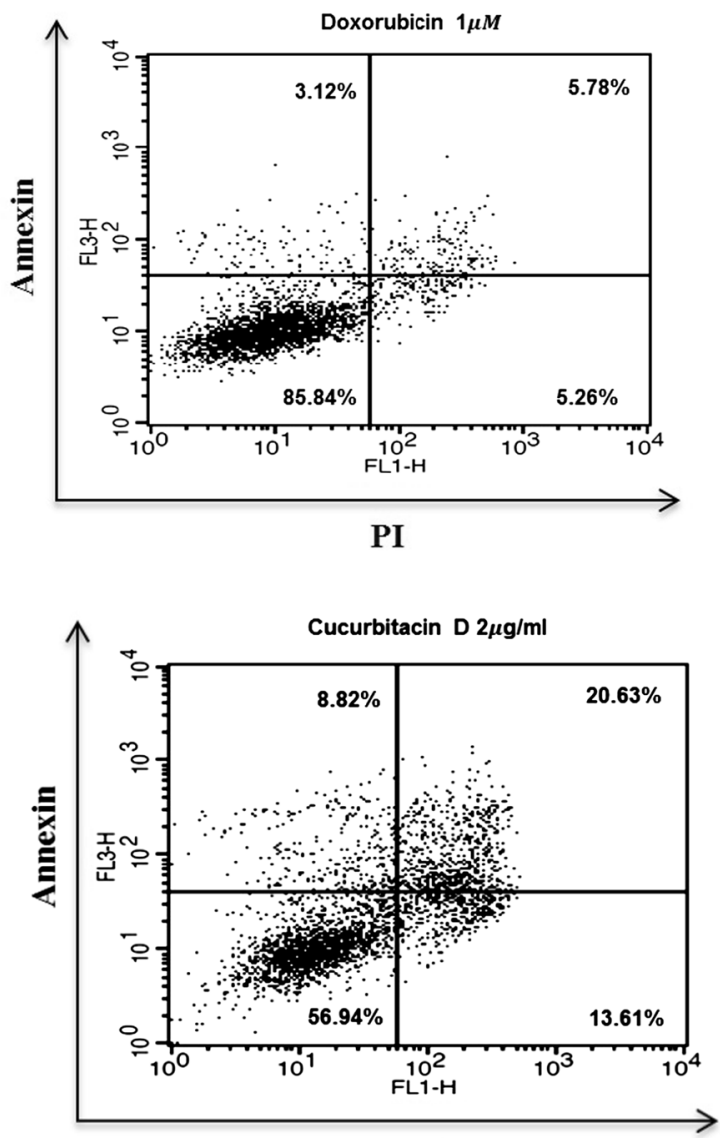

PI

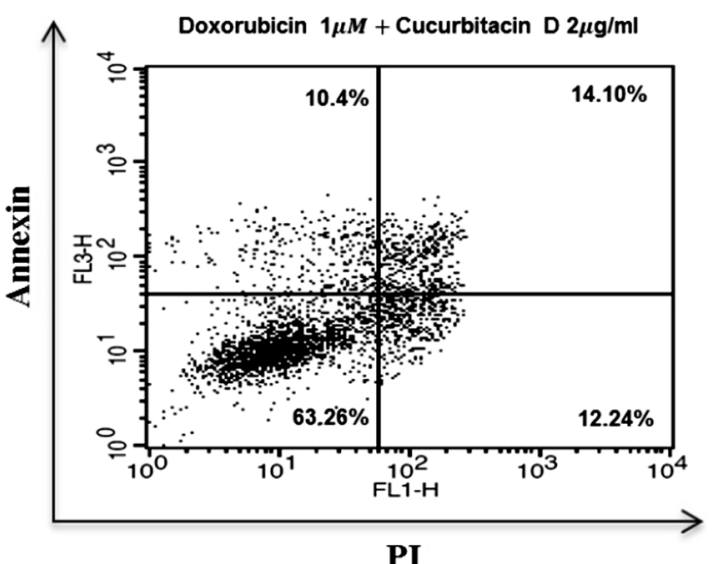

PI

Fig. 6 continued

Western blot in MCF7/ADR cells. Cucurbitacin D treatment resulted in a $114 \%$ increase in apoptosis when compared to that of control group. Additionally, results of Western blots demonstrate that cucurbitacin D up-regulated the levels of cleaved caspase-3, cleaved caspase-8, and cleaved PARP. Thereby, cucurbitacin D obviously induces apoptosis in MCF7/ADR cells. Because cucurbitacin D inhibits cell growth and induces apoptosis in doxorubicin-resistant breast cancer cells, MCF7/ADR, cucurbitacin D could be used as a useful compound to treat drug resistance. Targeting Stat 3 and NF- $\kappa B$ may also be useful to treat breast cancer. Our study clearly demonstrates that cucurbitacin D overcomes doxorubicin resistance in breast cancer cells. 


\section{Conclusions}

These results clearly demonstrate that cucurbitacin D could be used as a useful compound to overcome doxorubicin resistance.

Acknowledgments This research was supported by a Grant from Korean Medicine R\&D Project of the Ministry of Health and Welfare (B110043 and B120014).

\section{Compliance with Ethical Standards}

Conflict of interest The Authors declare that there is no conflict of interest that could be perceived as prejudicing the impartiality of the research reported.

Open Access This article is distributed under the terms of the Creative Commons Attribution 4.0 International License (http://creative commons.org/licenses/by/4.0/), which permits unrestricted use, distribution, and reproduction in any medium, provided you give appropriate credit to the original author(s) and the source, provide a link to the Creative Commons license, and indicate if changes were made.

\section{References}

1. Parkin DM, Bray F, Ferlay J, Pisani P (2005) Global cancer statistics, 2002. CA Cancer J Clin 55:74-108

2. Sledge GW, Neuberg D, Bernardo $P$, Ingle JN, Martino $S$, Rowinsky EK, Wood WC (2003) Phase III trial of doxorubicin, paclitaxel, and the combination of doxorubicin and paclitaxel as front-line chemotherapy for metastatic breast cancer: an intergroup trial (E1193). J Clin Oncol 21:588-592

3. Rabbani A, Finn RM, Ausio J (2005) The anthracycline antibiotics: antitumor drugs that alter chromatin structure. Bioessays 27:50-56. doi:10.1002/bies.20160

4. Szakacs G, Paterson JK, Ludwig JA, Booth-Genthe C, Gottesman MM (2006) Targeting multidrug resistance in cancer. Nat Rev Drug Discov 5:219-234. doi:10.1038/nrd1984

5. Zheng A, Kallio A, Harkonen P (2007) Tamoxifen-induced rapid death of MCF-7 breast cancer cells is mediated via extracellularly signal-regulated kinase signaling and can be abrogated by estrogen. Endocrinology 148:2764-2777. doi:10.1210/en.2006-1269

6. Taylor CW, Dalton WS, Parrish PR, Gleason MC, Bellamy WT, Thompson FH, Roe DJ, Trent JM (1991) Different mechanisms of decreased drug accumulation in doxorubicin and mitoxantrone resistant variants of the MCF7 human breast cancer cell line. Br J Cancer 63:923-929

7. Wang S, Kotamraju S, Konorev E, Kalivendi S, Joseph J, Kalyanaraman B (2002) Activation of nuclear factor-kappaB during doxorubicin-induced apoptosis in endothelial cells and myocytes is pro-apoptotic: the role of hydrogen peroxide. Biochem J 367:729-740. doi:10.1042/BJ20020752

8. Gariboldi MB, Ravizza R, Molteni R, Osella D, Gabano E, Monti E (2007) Inhibition of Stat 3 increases doxorubicin sensitivity in a human metastatic breast cancer cell line. Cancer Lett 258:181-188. doi:10.1016/j.canlet.2007.08.019

9. Barre B, Vigneron A, Perkins N, Roninson IB, Gamelin E, Coqueret O (2007) The STAT3 oncogene as a predictive marker of drug resistance. Trends Mol Med 13:4-11. doi:10.1016/j. molmed.2006.11.001

10. Hayden MS, Ghosh S (2012) NF-kappaB, the first quarter-century: remarkable progress and outstanding questions. Genes Dev 26:203-234. doi:10.1101/gad.183434.111
11. Atkinson GP, Nozell SE, Benveniste ET (2010) NF-kappaB and STAT3 signaling in glioma: targets for future therapies. Expert Rev Neurother 10:575-586. doi:10.1586/ern.10.21

12. Karin M, Lin A (2002) NF-kappaB at the crossroads of life and death. Nat Immunol 3:221-227. doi:10.1038/ni0302-221

13. Karin M (2009) NF-kappaB as a critical link between inflammation and cancer. Cold Spring Harb Perspect Biol 1:a000141. doi:10.1101/cshperspect.a000141

14. Bromberg J, Wang TC (2009) Inflammation and cancer: IL-6 and STAT3 complete the link. Cancer Cell 15:79-80. doi:10.1016/j. ccr.2009.01.009

15. Hirano T, Ishihara K, Hibi M (2000) Roles of STAT3 in mediating the cell growth, differentiation and survival signals relayed through the IL-6 family of cytokine receptors. Oncogene 19:2548-2556. doi:10.1038/sj.onc.1203551

16. Kamran MZ, Patil P, Gude RP (2013) Role of STAT3 in cancer metastasis and translational advances. Biomed Res Int 2013:421821. doi: $10.1155 / 2013 / 421821$

17. Darnell JE Jr (1997) STATs and gene regulation. Science 277:1630-1635

18. Schindler C, Darnell JE Jr (1995) Transcriptional responses to polypeptide ligands: the JAK-STAT pathway. Annu Rev Biochem 64:621-651. doi:10.1146/annurev.bi.64.070195.003201

19. Levy DE, Darnell JE Jr (2002) Stats: transcriptional control and biological impact. Nat Rev Mol Cell Biol 3:651-662. doi:10. 1038/nrm909

20. Jayaprakasam B, Seeram NP, Nair MG (2003) Anticancer and antiinflammatory activities of cucurbitacins from Cucurbita andreana. Cancer Lett 189:11-16

21. Chen JC, Chiu MH, Nie RL, Cordell GA, Qiu SX (2005) Cucurbitacins and cucurbitane glycosides: structures and biological activities. Nat Prod Rep 22:386-399. doi:10.1039/b418841c

22. Kim SR, Seo HS, Choi HS, Cho SG, Kim YK, Hong EH, Shin YC, Ko SG (2013) Trichosanthes kirilowii ethanol extract and cucurbitacin D inhibit cell growth and induce apoptosis through inhibition of STAT3 activity in breast cancer cells. Evid Based Complement Altern Med 2013:975350. doi:10.1155/2013/ 975350

23. Ding N, Yamashita U, Matsuoka H, Sugiura T, Tsukada J, Noguchi J, Yoshida Y (2011) Apoptosis induction through proteasome inhibitory activity of cucurbitacin D in human T-cell leukemia. Cancer 117:2735-2746. doi:10.1002/cncr.25711

24. Bowman T, Garcia R, Turkson J, Jove R (2000) STATs in oncogenesis. Oncogene 19:2474-2488. doi:10.1038/sj.onc.1203527

25. Buettner R, Mora LB, Jove R (2002) Activated STAT signaling in human tumors provides novel molecular targets for therapeutic intervention. Clin Cancer Res 8:945-954

26. Wang Y, Zhao GX, Xu LH, Liu KP, Pan H, He J, Cai JY, Ouyang DY, He XH (2014) Cucurbitacin IIb exhibits anti-inflammatory activity through modulating multiple cellular behaviors of mouse lymphocytes. PLoS ONE 9:e89751. doi:10.1371/journal.pone. 0089751

27. Huang S (2007) Regulation of metastases by signal transducer and activator of transcription 3 signaling pathway: clinical implications. Clin Cancer Res 13:1362-1366. doi:10.1158/10780432.CCR-06-2313

28. Kim JH, Lee SC, Ro J, Kang HS, Kim HS, Yoon S (2010) JNK signaling pathway-mediated regulation of Stat3 activation is linked to the development of doxorubicin resistance in cancer cell lines. Biochem Pharmacol 79:373-380. doi:10.1016/j.bcp.2009. 09.008

29. Vermeulen K, Van Bockstaele DR, Berneman ZN (2003) The cell cycle: a review of regulation, deregulation and therapeutic targets in cancer. Cell Prolif 36:131-149

30. King RW, Jackson PK, Kirschner MW (1994) Mitosis in transition. Cell 79:563-571 